Témoigner Témoigner. Entre histoire et mémoire

Getuigen Revue pluridisciplinaire de la Fondation Auschwitz

118 | 2014

Au nom des victimes. Dictature et terreur d'État en Argentine, Chili et Uruguay

\title{
Herinnering stand-by
}

De voormalige vernietigingskampen in Polen

Mémoire en stand by, les anciens camps d'extermination en Pologne

Memory standby, the former extermination camps in Poland

\section{OpenEdition}

1 Journals

Édition électronique

URL : http://journals.openedition.org/temoigner/1253

DOI : 10.4000/temoigner.1253

ISSN : 2506-6390

Éditeur :

Éditions du Centre d'études et de documentation Mémoire d'Auschwitz, Éditions Kimé

Édition imprimée

Date de publication : 1 octobre 2014

Pagination : 55-65

ISBN : 978-2-84174-674-3

ISSN : 2031-4183

Référence électronique

"Herinnering stand-by », Témoigner. Entre histoire et mémoire [Online], 118 | 2014, Online op 01 octobre 2015, geraadpleegd op 23 octobre 2020. URL : http://journals.openedition.org/temoigner/1253 ; DOI : https://doi.org/10.4000/temoigner.1253 


\section{Portfolio HERINNERING
STAND-BY}

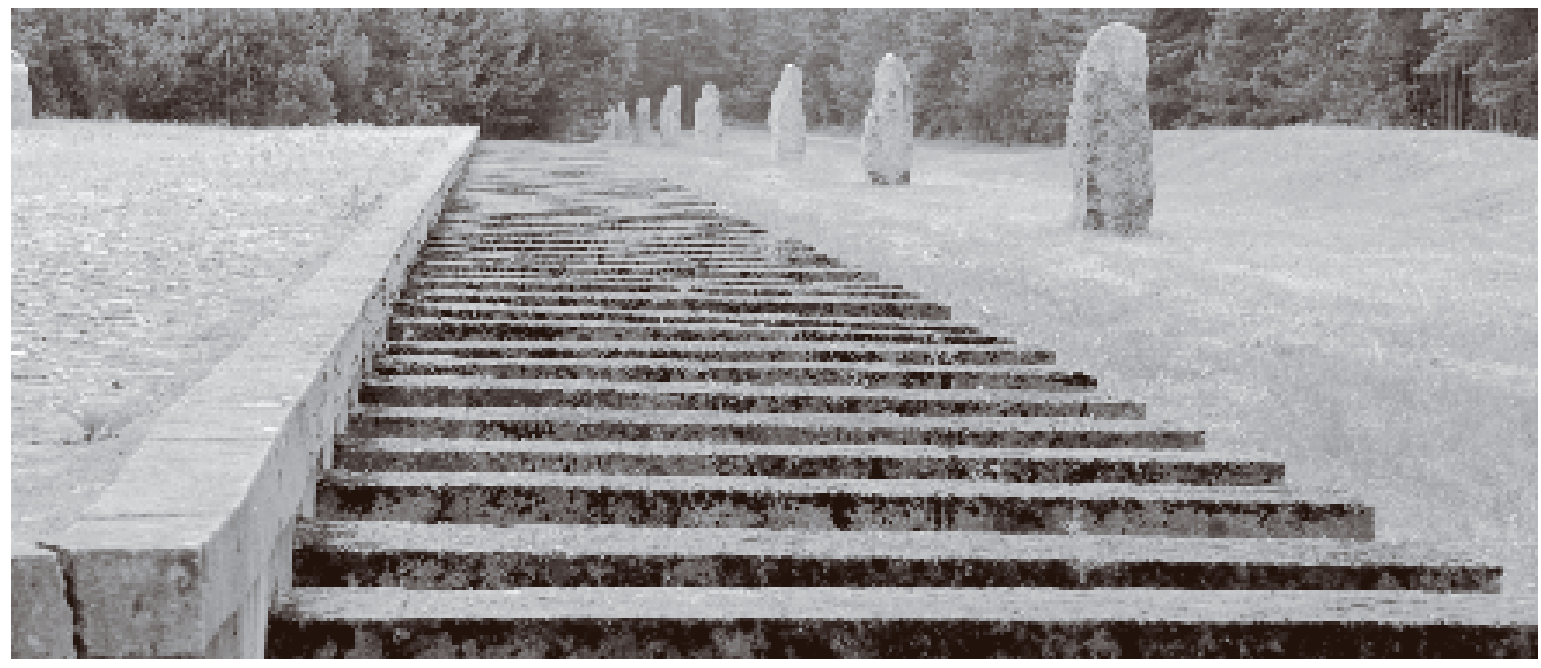

en, zijn dat niet. In deze gebieden, waar men niet moest werken om te serven, vinden we vandaag geen opvallende toegangspoort terug, geen slogan (Arbeit macht Frel, Jedem das sein) die het kwaad kan symboliseren in de Europese herinnering. Een aantal namen komt met moeite bovendrijven in het hedenarabs onafhankelijk van de Aktion Reinhardt), Treblinka, Sobibór, Belžec (de kampen van de Aktion Reinhard) en Majdanek (een gemengd kanp zoals Auschwitz, waar de SS de Joden en werkonbekwamen vergaste, en wa de anderegedporteerden meestal niet ontmanteld door de SS, daar werd niet ontmanteld door de SS, daar werde publiek leerde de sinistere plekken in Polen kennen dankzij Lanzmanns Shoah uit 1985. Maar hebben we werkelijk hun onhellspellende namen onthouden? Hebben zij werkelijk en plaats gekregen Guillaume Moscovitz (2005)? Ook al vornt Auschwitz zonder twijel het sluitstuk van de twee grote naziprojecten - de genocide en de concentratiekanpen -, toch kan de referentie 'Auschwitz' op zich geen compleet beeld geven van de omvang, de De foto's in de pertfio ton 

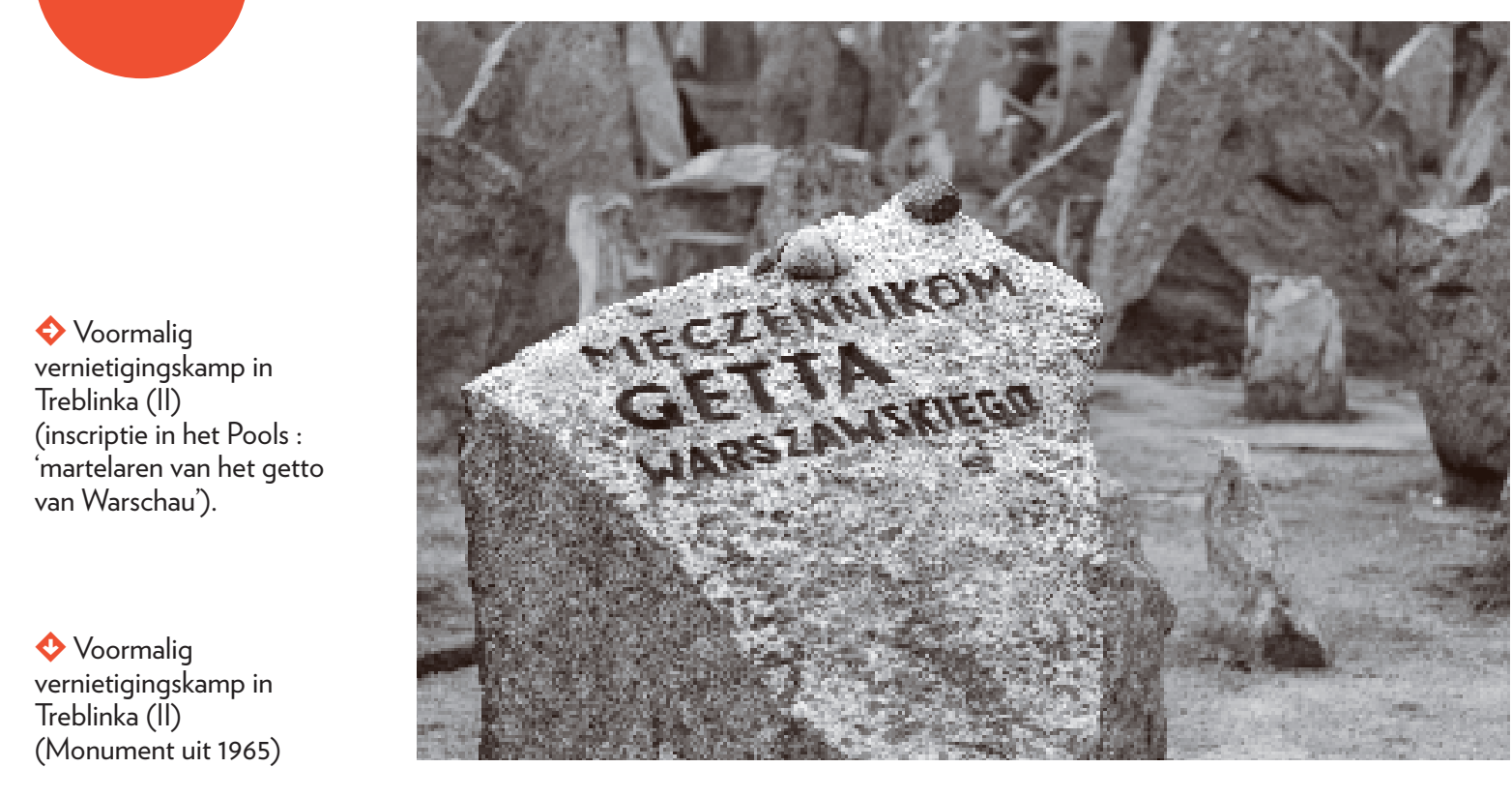

TREBLINKA I OPERATIONEEL TUSSEN 23 JULI 1942 EN 19 OKTOBER 1943 I BALLANS: 800 O00 DODEN

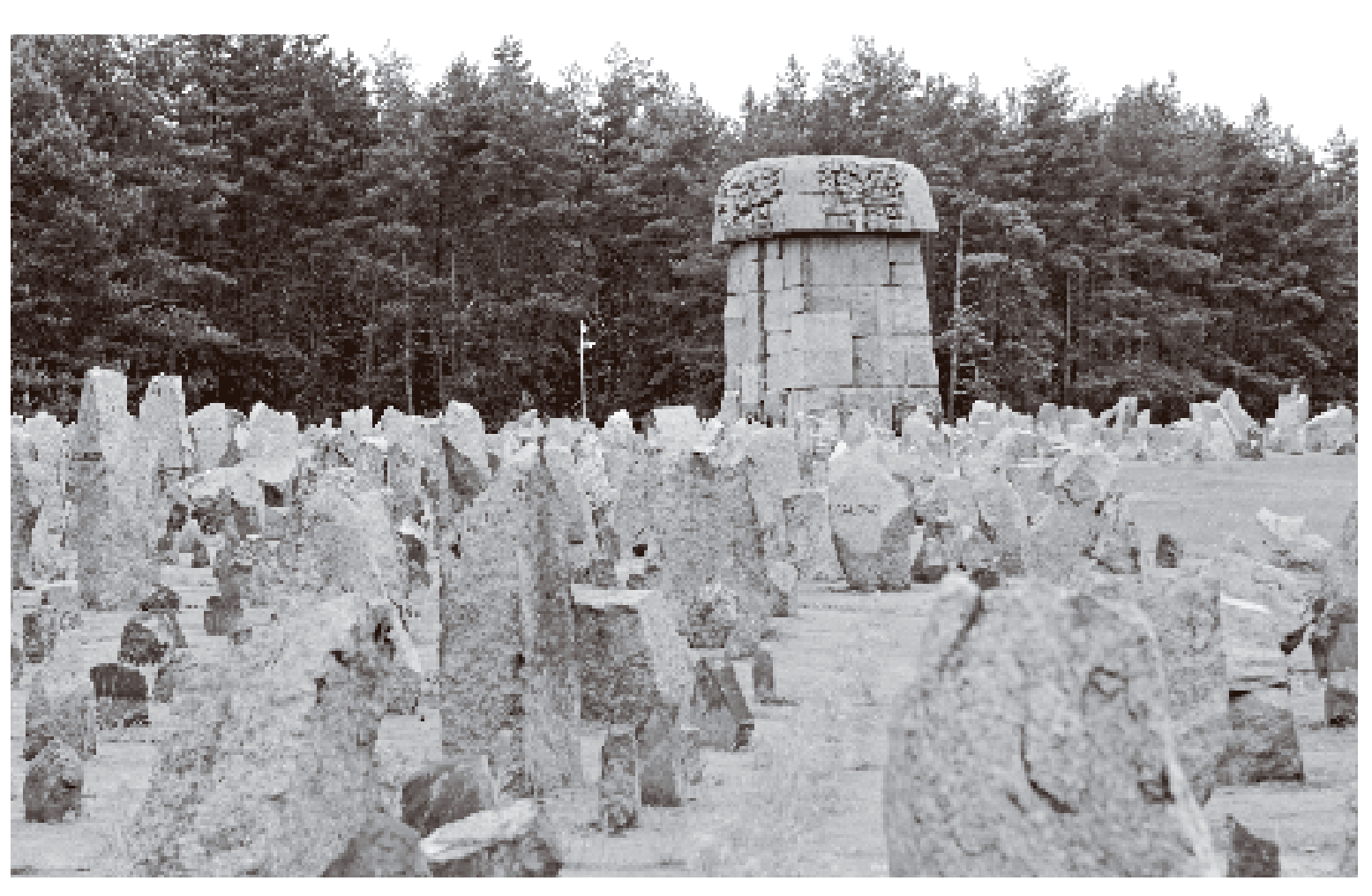

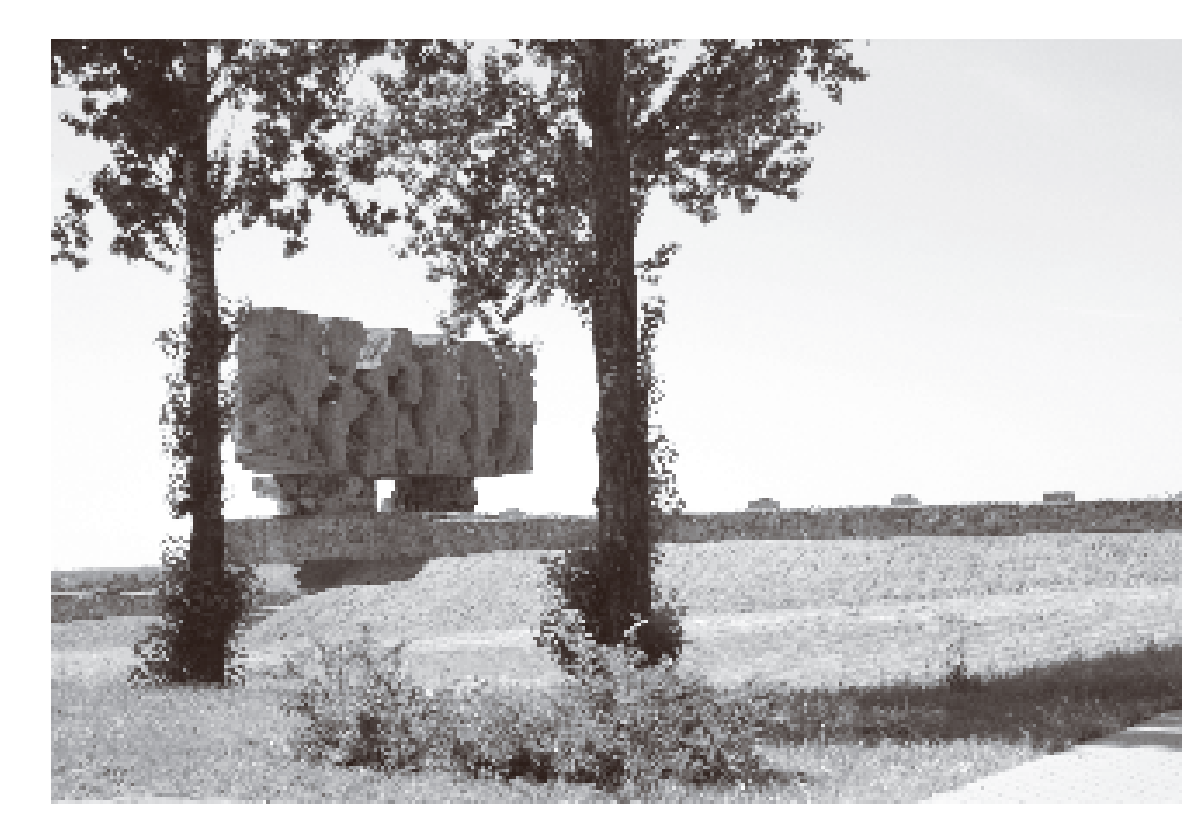

$\diamond$ Voormalig

vernietigingskamp in Lublin,

Majdanek.

MAJdANEK I OPERATIONEEL TUSSEN OKTOBER 1941 EN 23 JULI 1944 I BALANS : 80 OO0 DODEN

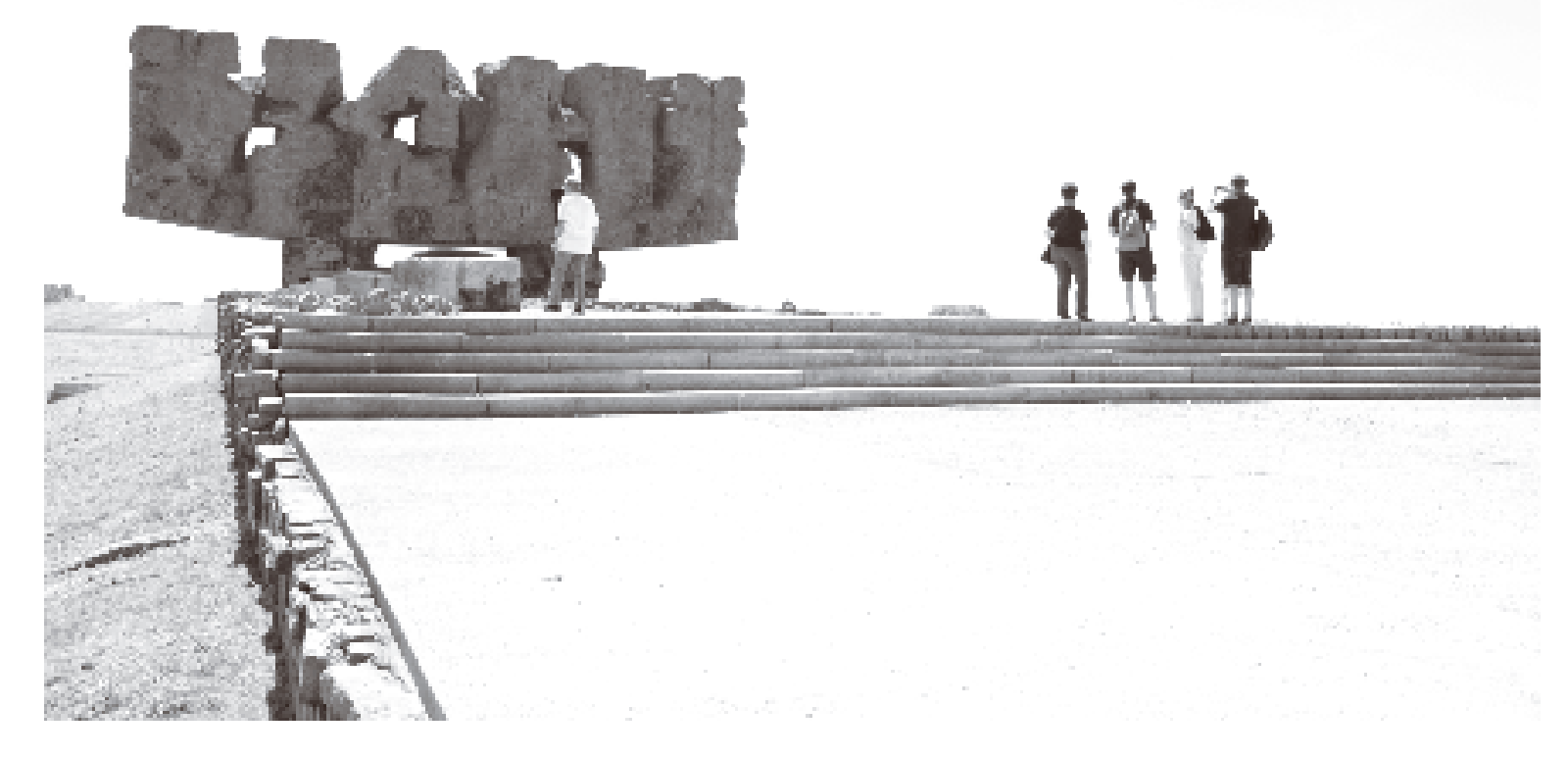



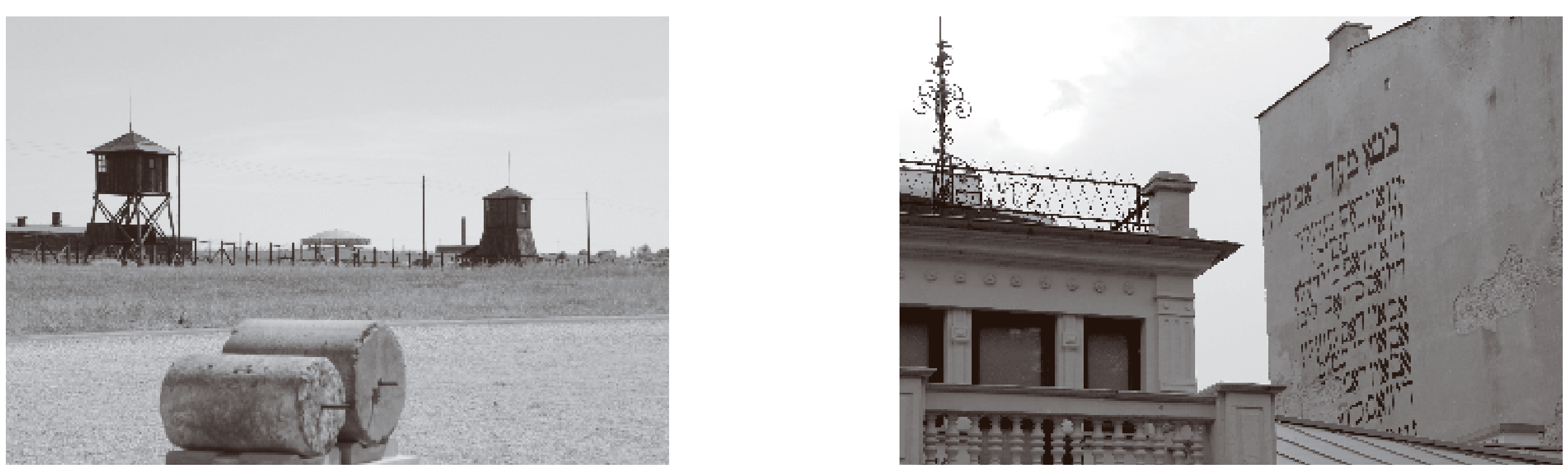

$\diamond$ Lublin.

en vernietigingskamp

in Lublin, Majdanek.

$\diamond$ Zicht op het

$\checkmark$ Mausoleum ontworpen

door Wiktor Totkin in 1969.
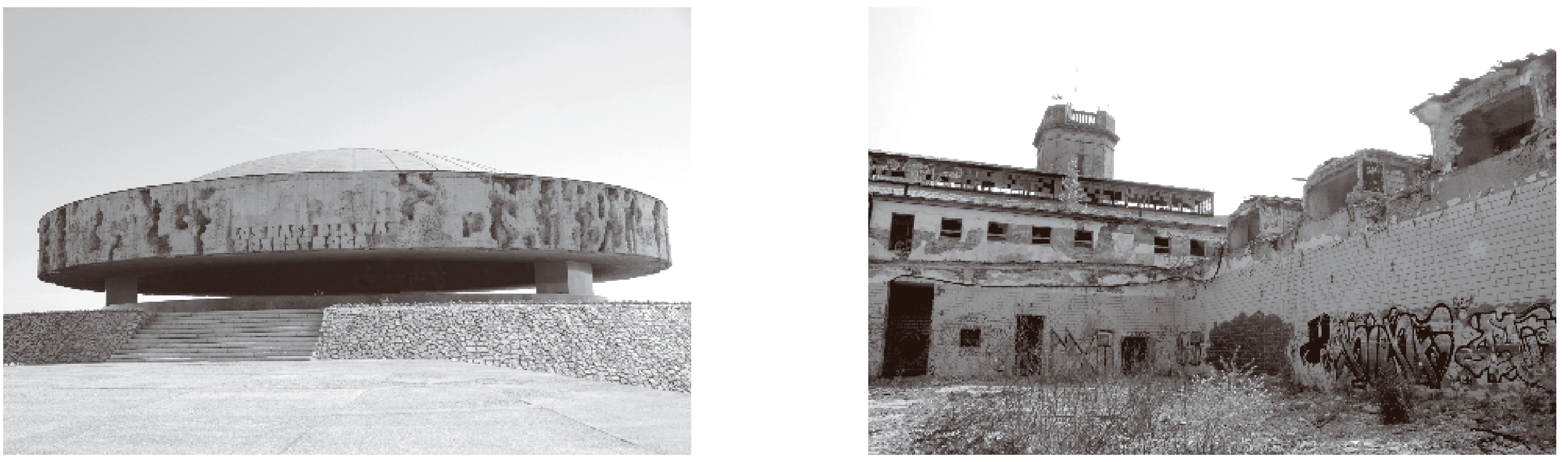

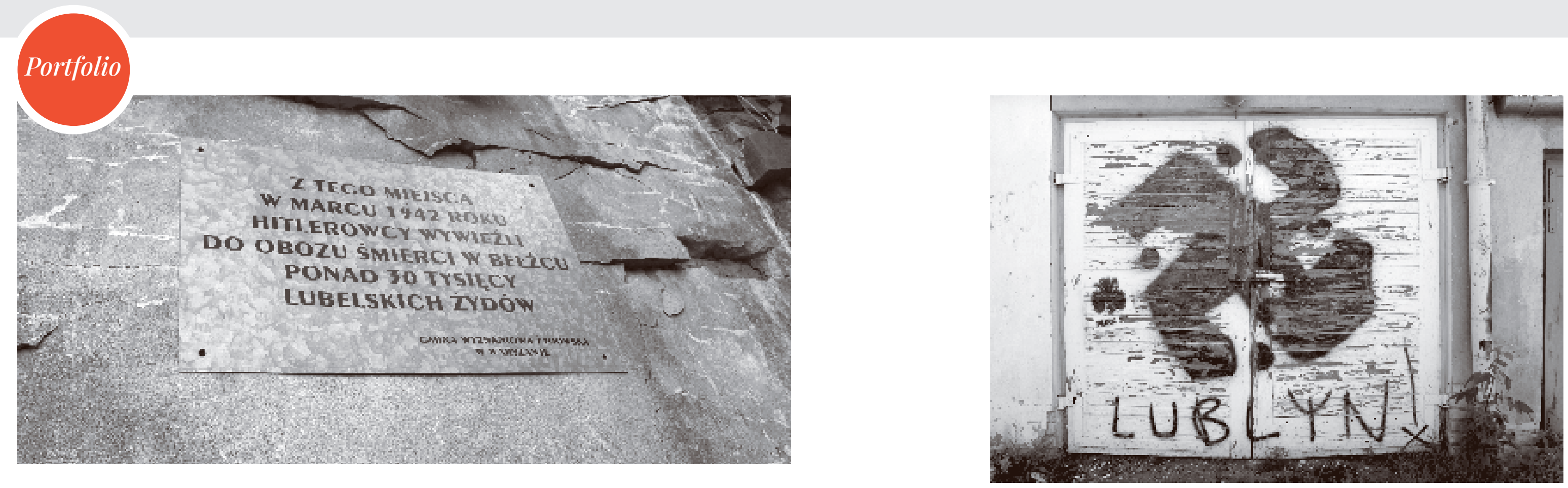

$\diamond$ Antisemitische

graffiti in Lublin

van de 'Aktion Reinhardt',

die werd uitgevoerd tussen

1941 en 1943).

Gedenkplaat op de Umschlagplatz van Lublin (inscriptie in het Pools:

van hieruit hebben de nazis in maart

1942 meer dan 30000 Joden

dodenkamp Betżec')

$\diamond$ Muur met gedenkplaat op de

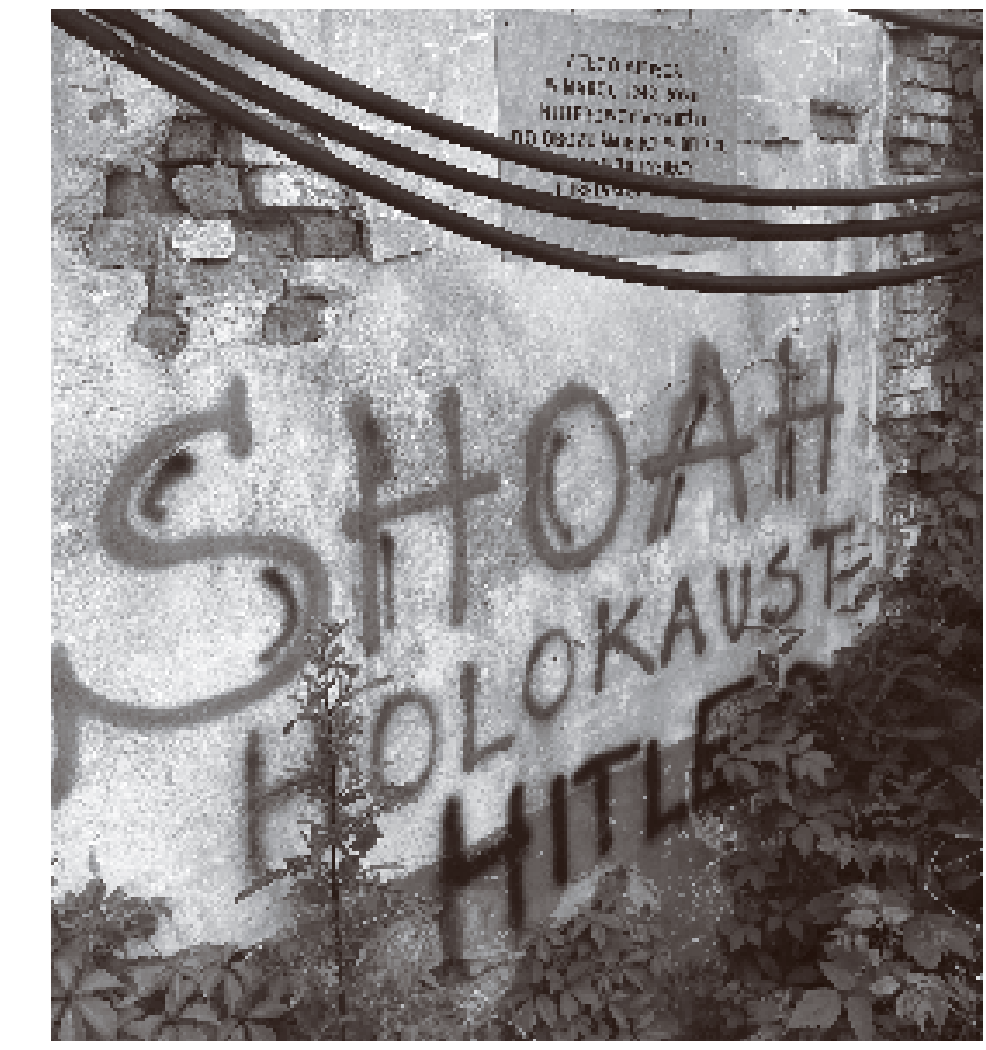

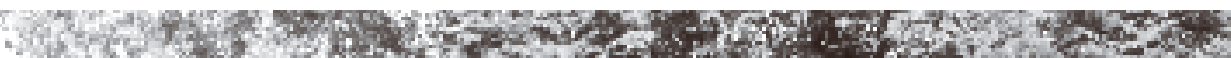

$\diamond$ Lublin :

nieuw Joods kerkhof.

Umschlagplatz van Lublin, graffiti.

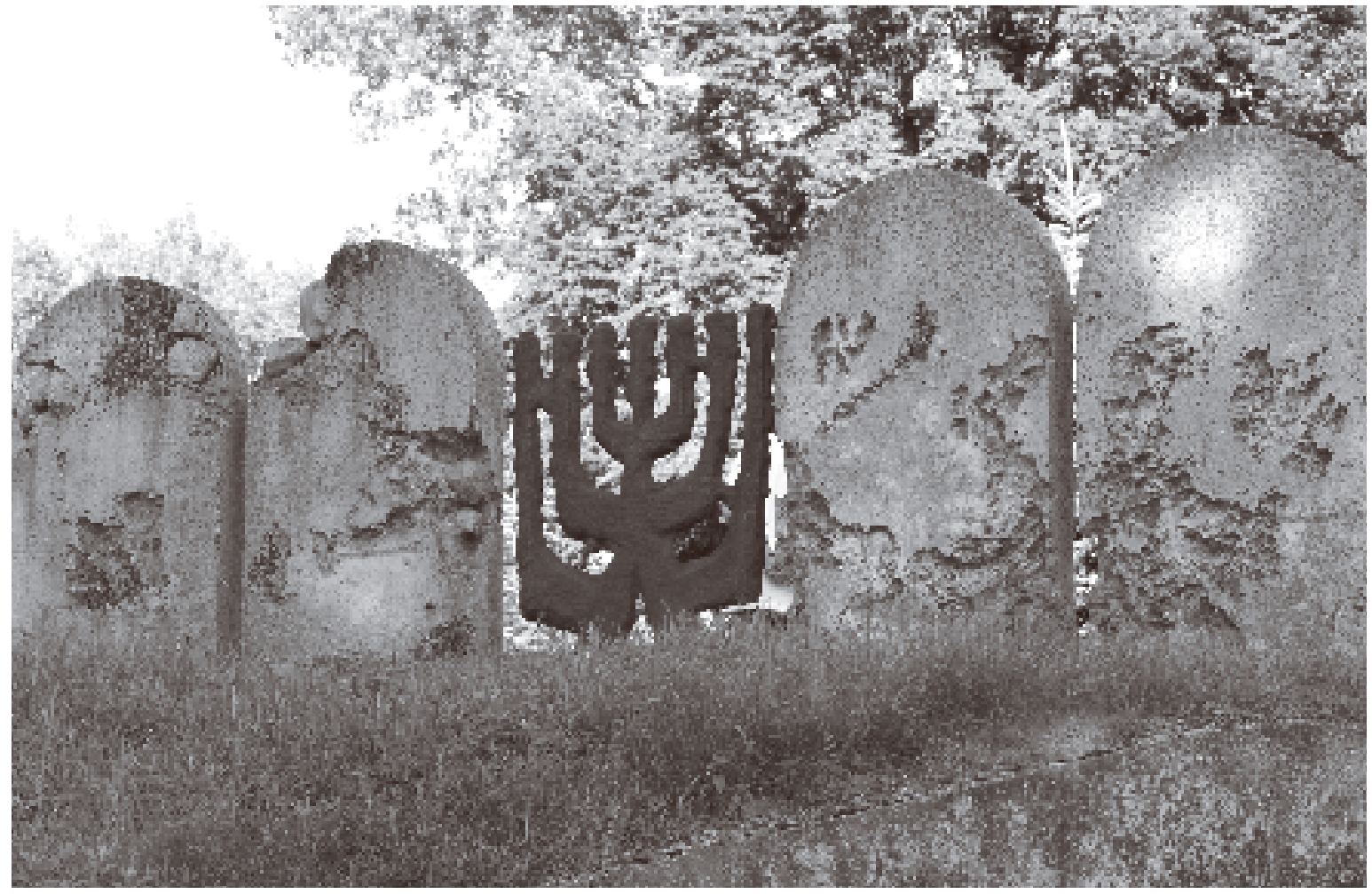



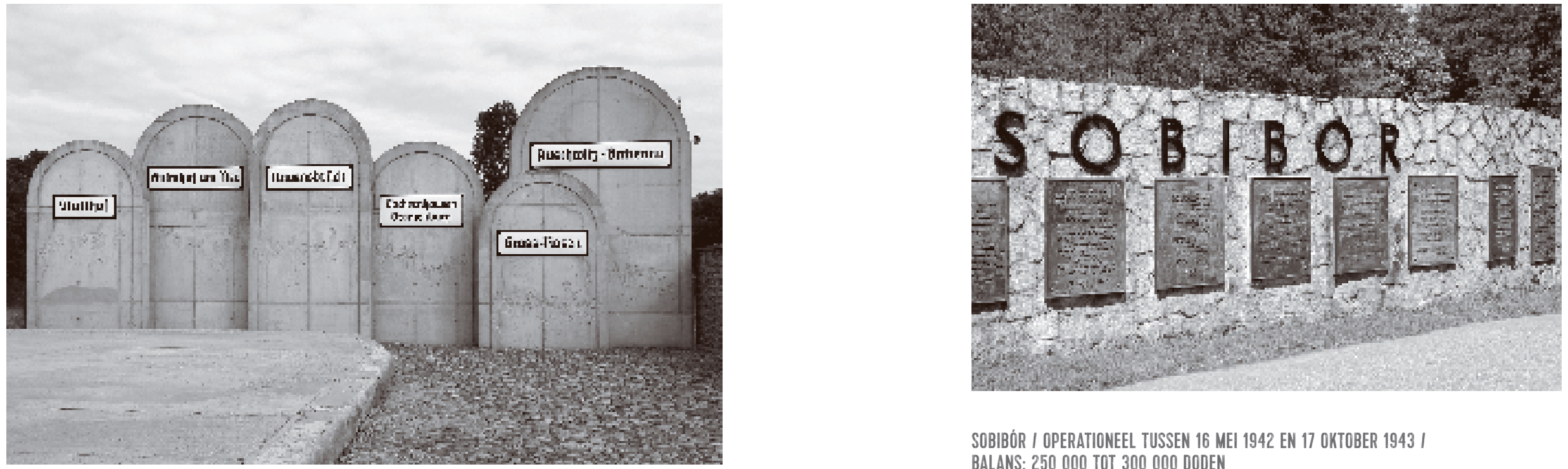

$\diamond \diamond$ Radegast deportatieplaats (Łódż)

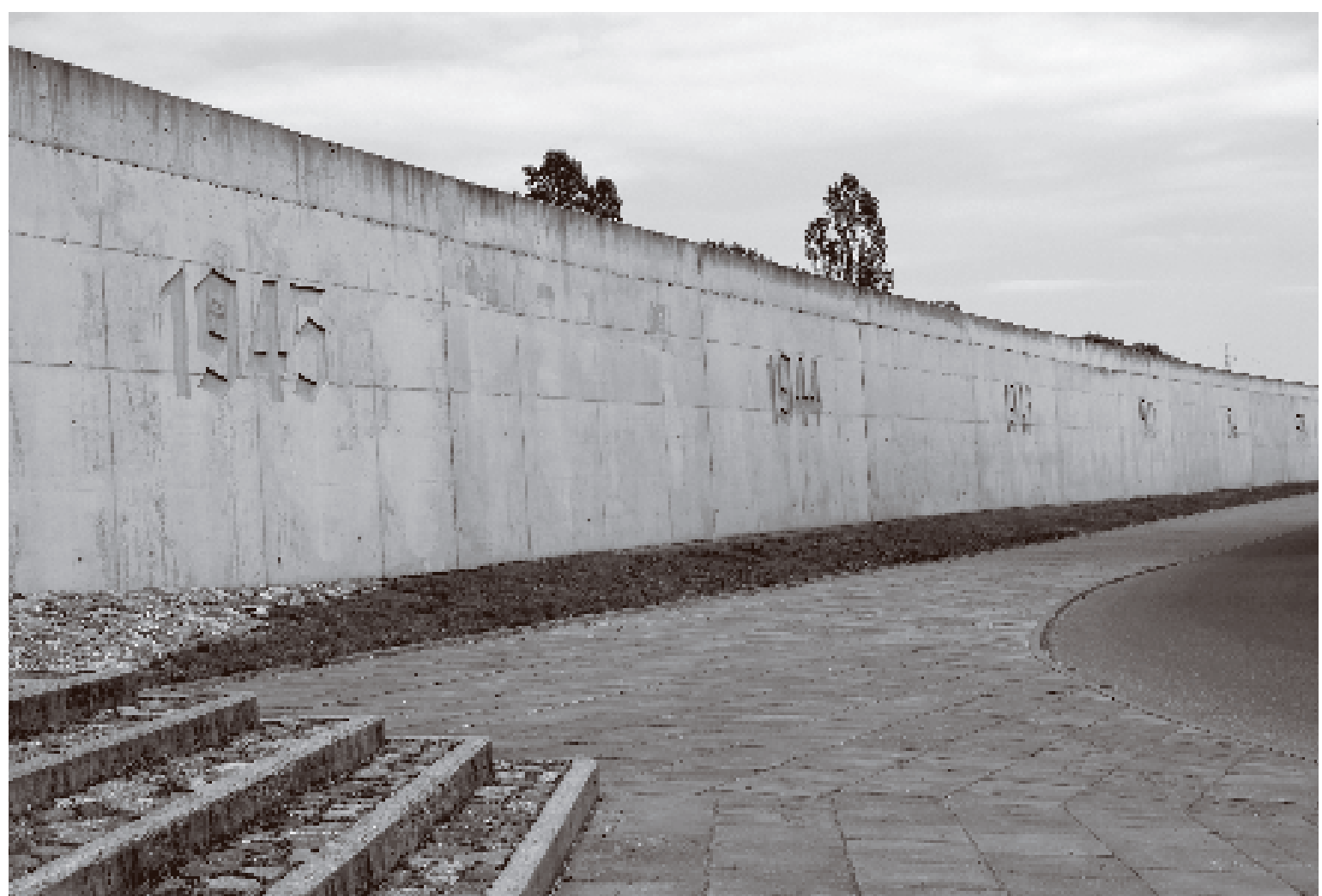

Voormalig vernietigingskamp

Sobibór.
SOBBBÓR I OPERRATIONEEL TUSSEN 16 MEL 1942 EN 17 OKTOBER 1943 I BALLNS: 250000 TOT 300000 DODEN

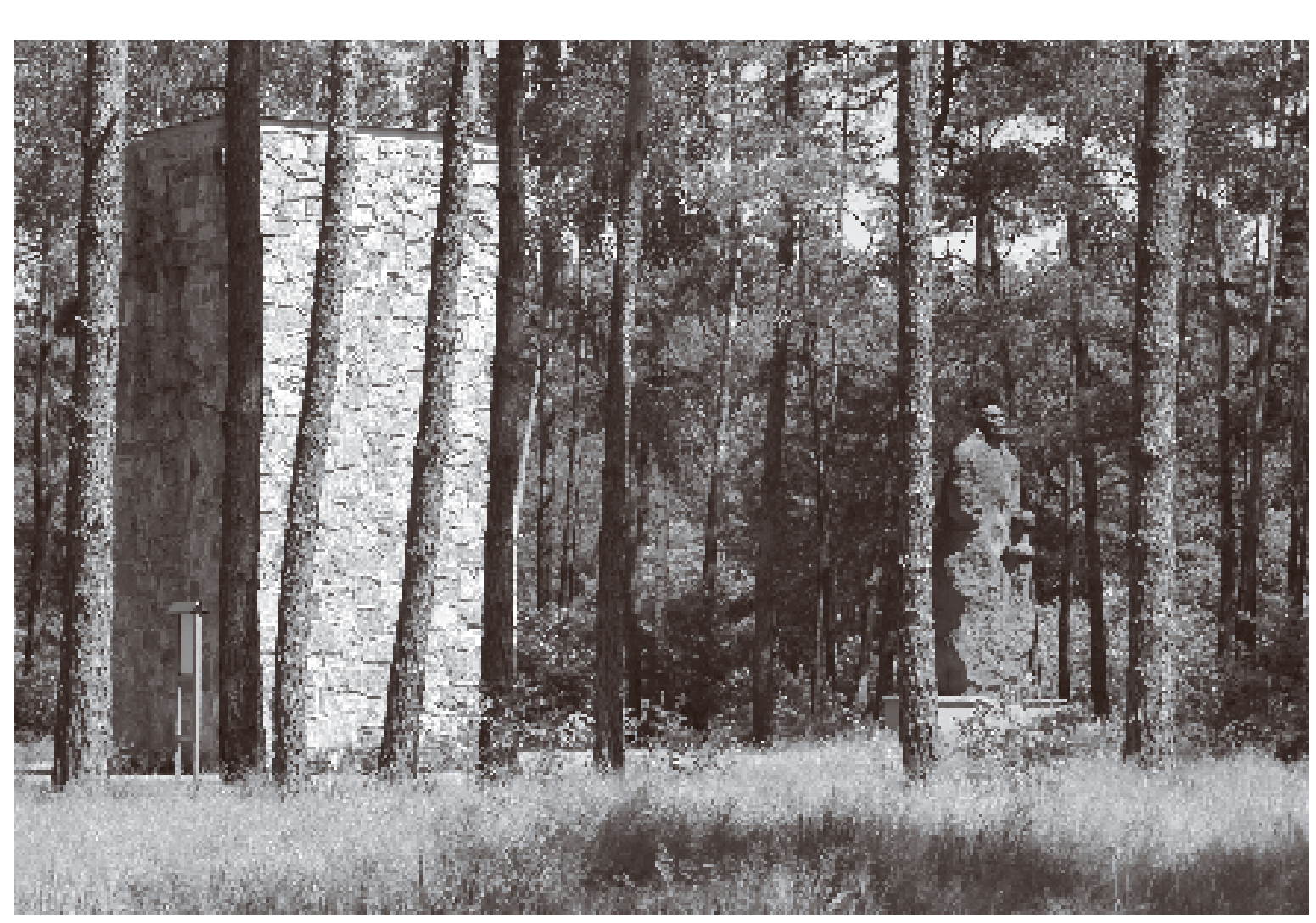




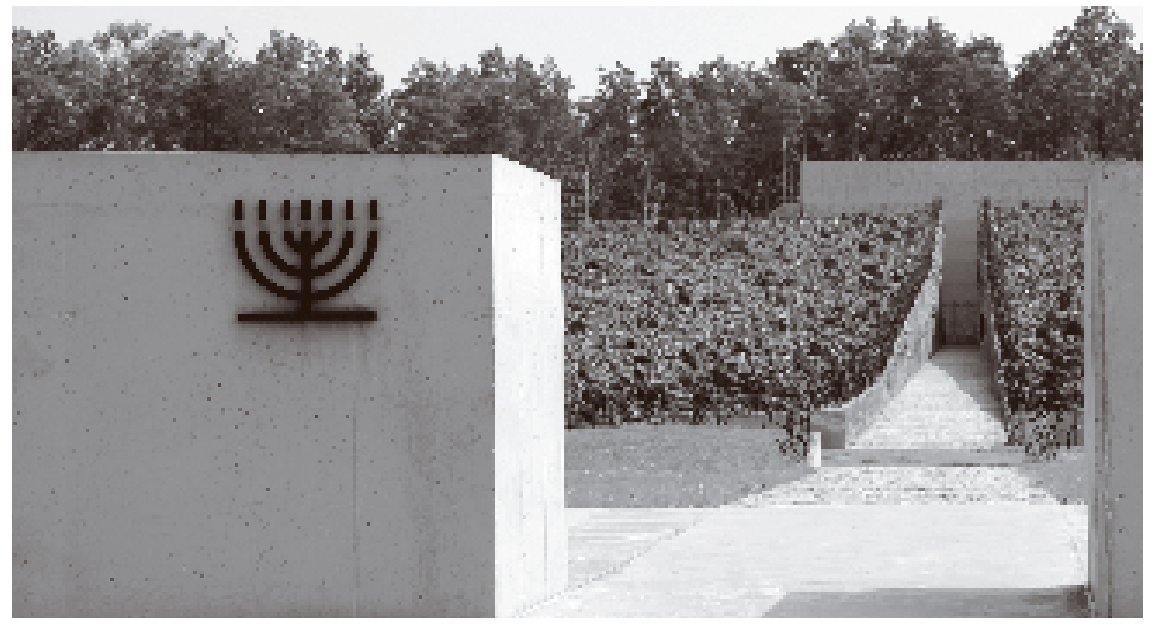

BeEzEE I OPERATIONEEL TUSSEN 17 MAART 1942 EN 12 DECEMBER 1942 I GeSCHATTE BALANS : 434000 TOT 600000 DODEN

Zicht op de gedenkplaats van het



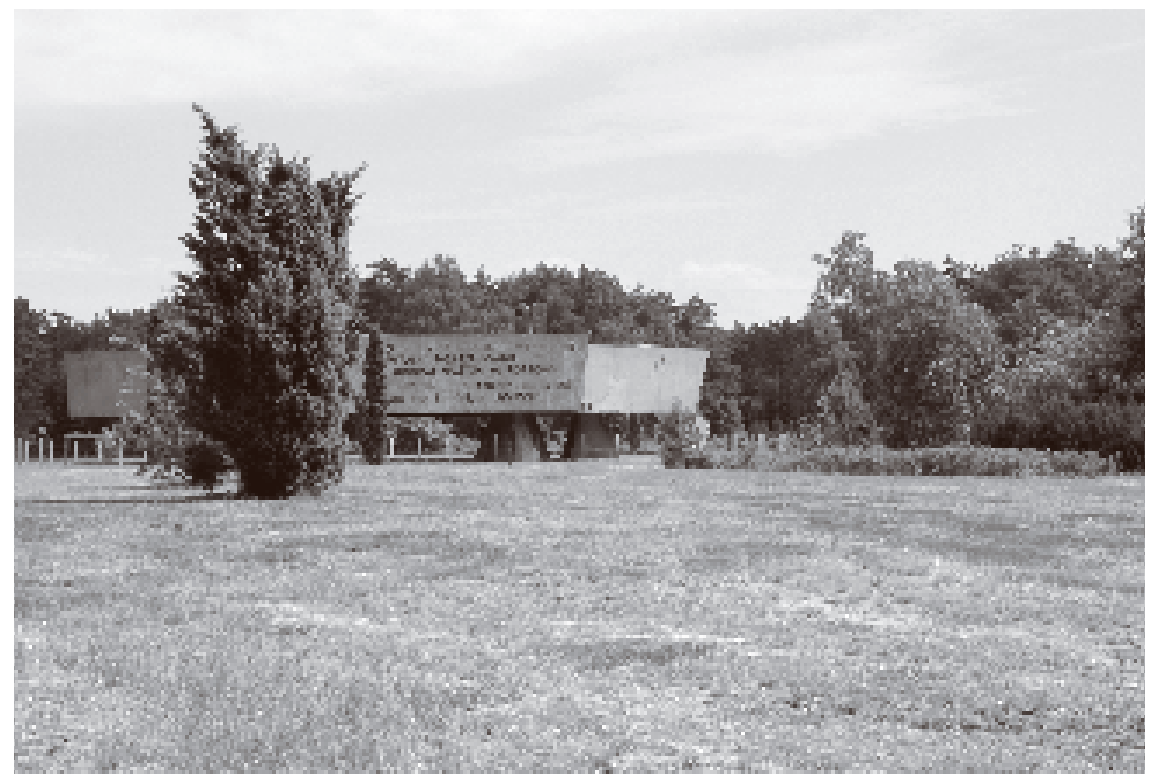

$\diamond \diamond$ Open plek in het bos van Rzuchów, niet ver

van het vernietigingskamp

Chełmno nad Nerem, waa de Joden werden verbrand nadat ze in vrachtwagen

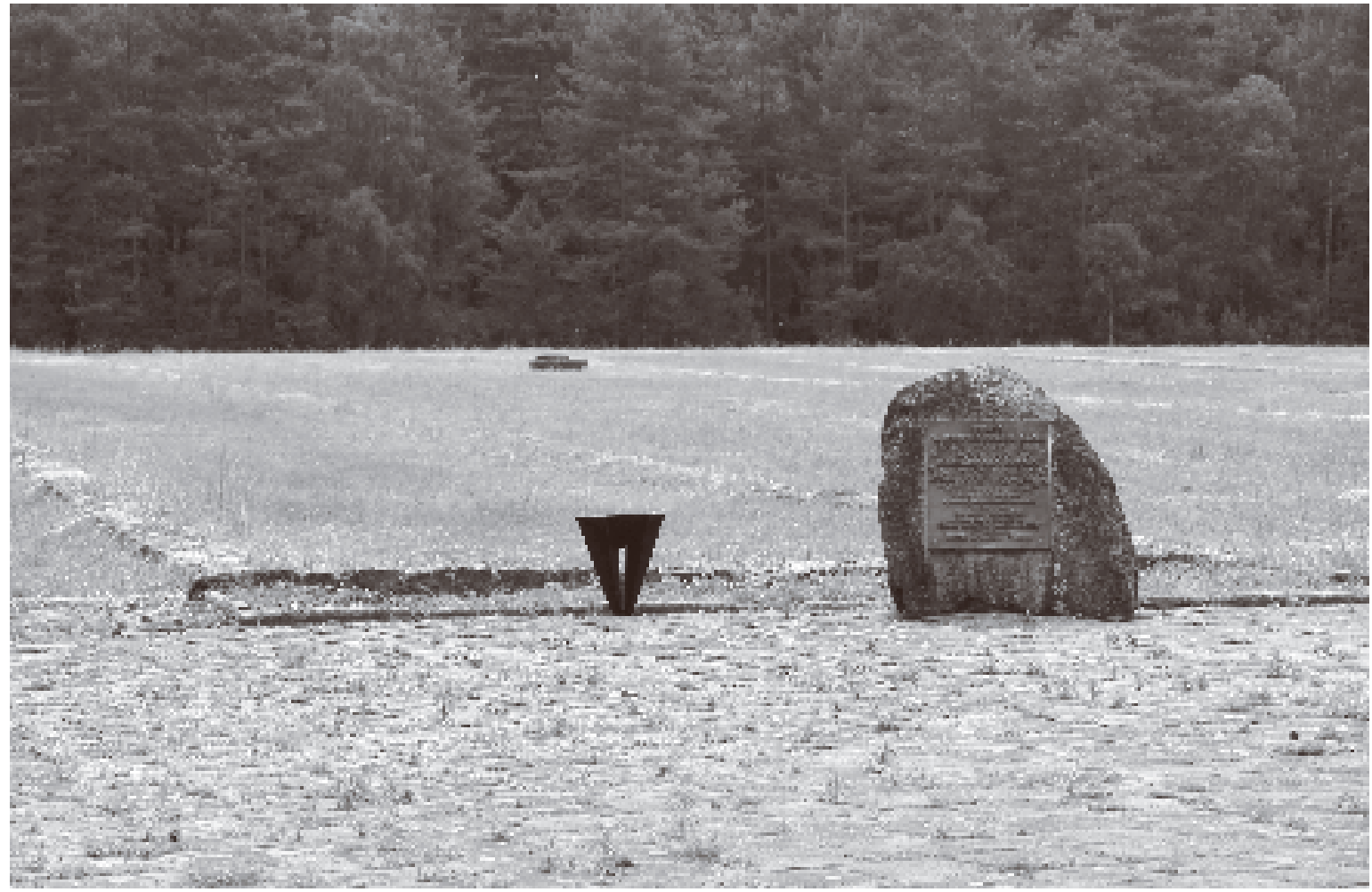

